REFERENCES

Barber, M., and Waterworth, P. M. (1962). Brit. med. J., 1, 1159.

Campbell, E. J. M. (1960). Ibid., 1, 457.

- and Howell, J B. L. (1960). Ibid., 1, 458

Elmes, P. C., Fletcher, C. M., and Dutton, A. A. C. (1957) Ibid., 2, 1272.

Goslings, W. R. O., Valkenburg, H. A., and Los, W. (1961). Bronchi:is: An International Symposium, edited by N. G. M. Orie and H J. Sluiter, p. 301. Royal Van Gorem. Assen, Netherlands.

Lockey, E., Eaton, B. R., and Compston, N. (1962). Brit. J. clin. Pract., 16, 13
McKerrow, C. B., McDermott, M., and Gilson, J. C. (1960). Lancet, 1, 149

May, J. R. (1953). Ibid., 2, 534

Medical Research Council (1960). Brit. med. J., 2, 1665

Mulder, J., Goslings, W. R. O., Van der Plas, M. C., and Lopes Cardozo, P. (1952). Acta med. scand., 143, 32.

Rawlings, G. A. (1953). Lancet, 2, 538.

Rollinson, G. N., and Stevens, S. (1961). Brit. med. J., 2, 191

Trafford, J. A. P., Maclaren, D. M., Lillicrap, D. A., Barnes, R. D. S., Houston, J. C., and Knox, R. (1962). Lancet, 1, 987.

Wright, B. M., and McKerrow, C. B. (1959). Brit. med. J., 2, 1041 .

\title{
FUSIDIC ACID: LABORATORY AND CLINICAL ASSESSMENT
}

BY

\author{
R. L. NEWMAN, M.R.C.S., L.R.C.P. \\ Registrar in Pathology
}

RUTH HACKNEY, M.B., B.Ch., D.P.H. Junior Hospital Medical Officer

\section{K. M. BHAT, M.B., B.S., D.C.H. Paediatric Registrar}

\section{CHIRISTINE ROBINSON}

Laboratory Technician

\section{G. T. STEWART, M.D. Pathologist}

\section{From Queen Mary's Hospital for Children, Carshalton}

Reports have recently been published on the laboratory (Godtfredsen et al., 1962 ; Barber and Waterworth, 1962 ; Hilson, 1962) and preliminary clinical (Scowen and Garrod, 1962; Taylor and Bloor, 1962) attributes of fusidic acid and its sodium salt ("fucidin"). In its chemical structure, relationship to cephalosporin $\mathbf{P}$ (Baird et al., 1961) and helvolic acid (Allinger and Coke, 1961), and in its selective antibacterial spectrum, this substance is of considerable interest. We are therefore presenting here a summary of our own assessment of fucidin in the laboratory and in the treatment of staphylococcal infections during the past two years.

\section{Microbiological Results}

Our results under this heading are largely in accordance with those previously reported (Godtfredsen, et al., 1962 ; Barber and Waterworth, 1962; Hilson, 1962). The following points deserve separate comment:

1. Of 200 fresh clinical isolates of penicillinase-forming Staphylococcus aureus, all except four were inhibited in nutrient broth by $0.1-1 \mu \mathrm{g}$. of fucidin per ml., provided the inocula were $10^{6}$ cells $/ \mathrm{ml}$. or less.

2. The minimal inhibitory concentration against staphylococci was closely dependent upon size of inoculum; large inocula $\left(>10^{6}\right.$ cells $/ \mathrm{ml}$.) of some strains resisted the action of fucidin at $10 \mu \mathrm{g} . / \mathrm{ml}$.

3. The effect of fucidin was bactericidal; with average inocula of most strains $\left(10^{4}-10^{5}\right.$ cells $\left./ \mathrm{ml}.\right), 30-60 \%$ of cells were killed in four hours and $80-95 \%$ in eight hours.

4. On agar flood-inoculated plates, all fresh isolates were well inhibited by disks of $1-10 \mu \mathrm{g}$. When heavy inocula were used, discrete colonies were present in the inhibitory zones; some of these colonies, titrated individually, were resistant to the drug at $10 \mu \mathrm{g} . / \mathrm{ml}$.

5. Serial passages of eight strains on agar plates containing rising gradients of fucidin produced slow acquisition of resistance during the first five days and a rapid increase thereafter, maintained on subculture in drug-free medium.

6. No destruction of fucidin was detected in 12-hour broth cultures, either of sensitive organisms growing in subinhibitory concentrations or of organisms with induced resistance growing at higher concentrations.

7. Fucidin was tested by the following methods for evidence of synergy with penicillin $G$ against penicillinase-forming staphylococci. (a) Liquid cultures were prepared, incorporating each drug, separately and together in chessboard fashion, in concentrations of $0.1-20 \mu \mathrm{g} . / \mathrm{ml}$. By this means each concentration of each drug was tested against all concentrations of the other drug for evidence of increased (or decreased) bactericidal effect by colony counts plated at four hours; differences in bacteriostatic activity were checked by turbidity readings after overnight growth. By this means an enhanced bactericidal effect against one penicillinase-forming strain (out of nine tested) was observed with a range of concentrations of $0.05-0.2 \mu \mathrm{g}$. of fucidin and $0.5-5 \mu \mathrm{g}$. of penicillin $\mathrm{G}$ per $\mathrm{ml}$. (b) Cellulose-acetate membranes (Courtaulds grade AP, $6 \mathrm{~cm}$.) were placed on poured agar plates incorporating an indicator organism (Oxford staphylococcus) with an inhibitory concentration of penicillin $\mathrm{G}(2 \mu \mathrm{g} . / \mathrm{ml}$.). Centrifuged cells from cultures of staphylococci grown in subinhibitory concentrations of fucidin were placed on top of the membranes and incubated overnight. The membrane was then removed and the plates were incubated for a further 18-24 hours. Penicillinase formed by the organisms diffused through the membrane,

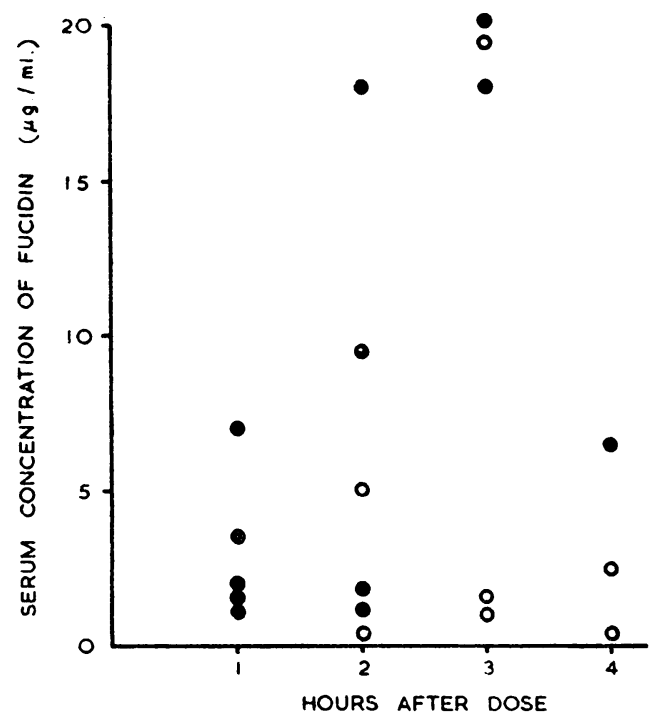

Serum concentrations of fucidin in subjects receiving: a single dose of $6 \mathrm{mg} . / \mathrm{kg}$. ; $20 \mathrm{mg}$. $/ \mathrm{kg}$. $/$ day in three doses. Assays on nutrient agar, using Oxford staph. as indicator organism and known concentrations of fucidin dissolved in serum. 
liberating the indicator organism in the zone immediately below. Tested thus, organisms grown in the presence of fucidin showed no diminution in penicillinase-formation. Instead of harvested cells, disks of agar containing penicillinase-forming staphylococci, with and without fucidin, were placed on these membrane-plates and similarly incubated; again no interference with penicillinaseproduction was demonstrated.

8. Acquisition of resistance to fucidin in vitro was not accompanied by any alteration in the minimal inhibitory concentration of penicillin $G$, or vice versa, against that strain.

\section{Pharmacology}

The actual concentrations of fucidin detected in serum after oral doses of $20 \mathrm{mg} . / \mathrm{kg}$./day, given approximately six-hourly, and after single doses of $6 \mathrm{mg} . / \mathrm{kg}$. are shown in the accompanying Chart. Assays in plasma or serum were difficult, for both albumin and, to a less extent, $\gamma$-globulin interfered with the bacteriostatic effect of fucidin in broth, though electrophoretically no specific zone of protein-binding was demonstrable. If allowance is made for this interfering effect of protein, fucidin may be presumed to reach a high bactericidal level in oral doses of $20 \mathrm{mg} . / \mathrm{kg}$. $/$ day. We have no other evidence of whether protein in the serum or in exudates interferes with the activity of fucidin in vivo. The drug was detected only in trace amounts in the urine during treatment.

\section{Clinical Studies}

\section{Treatment of Nasal Carriers of Staph. Aureus}

Fucidin was incorporated $(1 \%)$ in a simple cream and applied topically to the nares thrice daily for two to five days in 45 chronic nasal carriers of Staph. aureus. Swabs taken subsequently (Table I) showed that all but

TABle I.-Results of Treatment of Nasal Carriers of Staph. ciureus with Fucidin

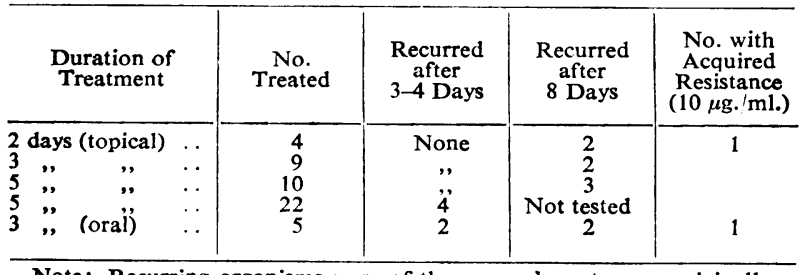

Note: Recurring organisms were of the same phage type as originally.

four cases were clear of infection three to four days after the end of treatment, but there were seven recurrences after eight days. Of five similar cases treated orally $(20 \mathrm{mg} . / \mathrm{kg}$./day in three daily doses), three were clear of infection eight days later. Two re-isolated strains had acquired resistance, approximately tenfold, to fucidin.

A cross-over comparison of fucidin with chlorhexidine was then made. Thirty-seven children, all nasal carriers of Staph. aureus, were treated by thrice-daily application to the nares of either chlorhexidine or fucidin cream, each followed in relapsing cases by the other. The results (Table II) showed that, of the 15 treated

TABLE II.-Cross-over Trial of Fucidin and Chlorhexidine in Nasal Carriers of Staph. aureus

\begin{tabular}{c|c|c|c|c|c}
\hline Series & \multicolumn{1}{|c|}{$\begin{array}{c}\text { First } \\
\text { Drug }\end{array}$} & No. & $\begin{array}{c}\text { Not } \\
\text { Cleared }\end{array}$ & $\begin{array}{c}\text { Second } \\
\text { Drug }\end{array}$ & $\begin{array}{c}\text { Not } \\
\text { Cleared }\end{array}$ \\
\hline $\begin{array}{c}\text { A } \\
\text { B }\end{array}$ & $\begin{array}{l}\text { Chlorhexidine } \\
\text { Fucidin }\end{array}$ & $\begin{array}{c}15 \\
22\end{array}$ & $\begin{array}{c}10 \\
4\end{array}$ & $\begin{array}{l}\text { Fucidin } \\
\text { Chlorhexidine }\end{array}$ & $\begin{array}{c}1 \\
x^{2}=7 \cdot 7 ; 0.05>\mathbf{P}>0.02 .\end{array}$
\end{tabular}

with chlorhexidine first, 5 were clear of the organism two days after the end of treatment; of the remaining 10,9 were successfully treated with fucidin; of 22 treated with fucidin, 4 still had the organism after treatment, 2 of which were cleared with chlorhexidine.

Treatment of Active Infections Due to Staph. aureus Seven children were treated with $20 \mathrm{mg} . / \mathrm{kg} . / \mathrm{day}$, divided into three doses, given approximately every eight hours.

Case 1.-An 11-month-old girl with gastroenteritis due to Staph. aureus had the same organisms in her nose and throat. Treatment with fucidin orally resulted in symptomatic improvement, with clearance of the organisms from the stool, throat, and nasal swabs after five days.

Case 2.-A 4-months-old boy who had failed to thrive after a pyloroplasty had suffered from a number of infections, including enteritis due to Staph. aureus, which had been successfully treated with methicillin. He then acquired an upper respiratory infection and Staph. aureus was grown freely from his throat and nasal swabs. Clearance of the organism was achieved after oral treatment with fucidin for five days.

Case 3.-A 4-months-old boy who had had a repair operation for a meningomyelocele developed a wound infection with Staph. aureus which resisted treatment with chloramphenicol. Extensive sloughing of the wound edges occurred and there was a considerable purulent exudate. Fucidin was given orally and within two days the child was better clinically. After five days the base of the sloughed area was clean and granulating, although Staph. aureus was still present in swabs from the lesion. One month later granulations had reached the level of the surface and the area had healed to a quarter of its original size.

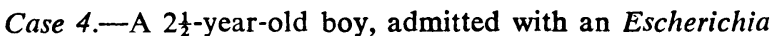
coli type 0111 infection, was treated with neomycin. The E. coli was eradicated but a superinfection with Staph. aureus developed and diarrhoea continued. After treatment with fucidin the diarrhoea ceased; the staphylococcus disappeared in 48 hours and was not isolated from the stools thereafter.

Case 5.-A 12-year-old girl with paraplegia and a permanent tracheotomy developed a respiratory infection with Staph. aureus. This had been unsuccessfully treated with tetracycline. It was difficult to be certain in this case that the organism was causing a pulmonary infection, but it was freely cultured from the mucopus from the tracheotomy stoma. It disappeared during treatment with fucidin and remained absent for about seven days thereafter, at the end of which time colonization with a different strain of Staph. aureus and a pneumococcus occurred.

Case 6.-A 3-year-old boy with fibrocystic disease of the pancreas and staphylococcal pneumonia due to Staph. aureus type $80 / 81$ was treated with a new isoxyazolyl derivative of 6-APA. This produced clinical improvement but failed to eradicate the infection completely, scanty or moderate numbers of organisms being repeatedly cultured from the pharynx. Treatment with fucidin resulted in the elimination of Staph. aureus from the pharyngeal swabs after nine days and from several subsequent swabs.

Case 7.-A mentally defective girl, aged 12 years, had chronic osteomyelitis of the humerus with sequestrum formation. Difficulty had been encountered in treatment because of her marked allergy to all penicillins. A large cystic soft-tissue swelling was present, aspiration of which yielded Staph. aureus with uniform sensitivity to fucidin at $0.1 \mu \mathrm{g} . / \mathrm{ml}$. in broth. Treatment with fucidin was begun and continued during the subsequent sequestrectomy. The swelling subsided a little during the first 12 days of treatment. but Staph. aureus was readily cultured from the sequestrum and fragments of bone which were removed at operation. On this occasion numerous variant colonies were present which showed an increase in minimal inhibitory concentration to 
50-100 $\mu \mathrm{g} . / \mathrm{ml}$. These variants maintained their increased resistance on subculture. (Assay of fucidin in the operation specimens showed levels from 0.8 to $6.5 \mu \mathrm{g}$. $/ \mathrm{ml}$.) After operation fucidin was continued for a further week, but pyrexia continued and the swelling of the arm failed to subside. Treatment was therefore discontinued in favour of erythromycin ; no further opportunity for isolation of the organism occurred, but the infection gradually subsided over a period of six weeks into an indolent state.

One additional patient received topical treatment, as follows :

Case 8.-An 11-year-old boy was operated on for repair of a cleft palate and developed a Staph. aureus wound infection. Fucidin cream was applied topically for five days. This resulted in disappearance of the organism from the wound, which bealed satisfactorily.

Examination of the urine, haemoglobin, and leucocytes after therapy in these patients disclosed no abnormalities attributable to the drug; no signs of intolerance were detected.

\section{Discussion}

In these studies fucidin showed pronounced bactericidal activity against $99 \%$ of clinical isolates of Staph. aureus in concentrations which are easily attainable, and well tolerated, in topical application to the skin, anterior nares, and wound surfaces. In fresh isolates of Staph. aureus the majority of the cells are sensitive to fucidin $(0.1-1 \mu \mathrm{g} . / \mathrm{ml}$.), but on serial passage in vitro resistance develops quickly and intensively. Some strains, even on first isolation, contain cells resistant to $10 \mu \mathrm{g} . / \mathrm{ml}$.

According to other workers (Godtfredsen et al., 1962 ; Barber and Waterworth, 1962; Scowen and Garrod, 1962 ; Taylor and Bloor, 1962) a mixture of fucidin and penicillin $G$ acts synergistically upon large inocula of certain strains of Staph. aureus. Barber and Waterworth (1962) found that this depended upon the fucidin in the mixture inhibiting multiplication sufficiently to delay destruction of the penicillin for two to four hours, after which any fucidin-resistant mutants were killed by penicillin, so that the combination was strongly bactericidal even to a large inoculum. In their experiments, and in ours, this effect was observed only with certain penicillinase-forming staphylococci, and even then only within a narrow optimal ratio of the two drugs which would be difficult if not impossible to arrange in vivo.

Applied topically thrice daily for two to five days, fucidin promoted immediate clearance of Staph. aureus from the nares of 68 out of 77 chronic nasal carriers. No adverse effects were noted, but seven individuals showed recurrence of infection eight days later; two re-isolated strains of the organism showed drug-resistance, one being derived from a group of five cases receiving oral treatment which was in this respect less successful. One child with a post-operative infection of a cleft palate repair was treated by intensive topical application, again with a satisfactory result.

Systemic treatment of six relatively mild staphylococcal infections produced satisfactory clinical and bacteriological response. In one severe infection (chronic osteomyelitis) the lesion subsided slightly at first, but at operation the organism was freely re-isolated from granulation tissue and from the sequestrum, with a large proportion of highly resistant mutants, though the level of fucidin in the excised tissue was as high as could be expected.
These results indicate that oral administration of fucidin $(20 \mathrm{mg}$. $/ \mathrm{kg}$. / day) appears to produce satisfactory levels in the plasma and in certain infected tissues. There is no evidence of toxicity in this or in other studies (Godtfredsen et al., 1962 ; Scowen and Garrod, 1962 ; Taylor and Bloor, 1962), but the metabolic pathway of the drug is obscure ; some may be excreted in the bile and faeces, which would explain its effectiveness in clearing sensitive cocci from the gut. But the drug is scarcely detectable in the urine, so it is presumably partly converted into inactive conjugates or metabolites. Its precise fate in the body is therefore uncertain, and until more data about this are available it would seem prudent to restrict its use to cases in which the organism is resistant or the infection refractory to other drugs. If the infecting staphylococcus is not immediately eradicated, drug-resistance of a high order can emerge rapidly. Synergy with penicillin $G$ appears to be a theoretical rather than a practical possibility.

\section{Summary}

Fusidic acid ("fucidin ") has a powerful bactericidal action upon Staph. aureus. Resistant variants are present in some strains at first isolation and a high degree of drug-resistance occurs quickly on passage.

Given orally, the drug showed therapeutic activity in six out of seven staphylococcal infections ; in one case, that of chronic osteomyelitis, the organism acquired a high degree of drug resistance within two weeks.

Applied topically, fusidic acid promoted immediate clearance of Staph. aureus from 68 out of 77 established carriers, and appeared in this respect to be significantly more active than chlorhexidine. In two relapsing carriers the re-isolated organisms showed drug-resistance.

Acknowledgment is made to our colleagues in the hospital for their co-operation; and to Leo Laboratories Ltd. for supplies of fucidin.

\section{REFERENCES}

Allinger, N. L., and Coke, J. L. (1961). J. org. Chem., 26, 4522. Baird, B. M., Halsall, T. G., Jones, E. R. H., and Lowe, G. (1961). Proc. chem. Soc., 257.

Barber, Mary, and Waterworth, Pamela M. (1962). Lancet, 1 , 931 .

Godtfredsen, W., Roholt, K., and Tybring, L. (1962). Ibid., 1, 928.

Hilson, G. R. F. (1962). Ibid., 1, 932.

Scowen, E. F., and Garrod, L. P. (1962). Ibid., 1, 933.

Taylor, G., and Bloor, K. (1962). Ibid., 1, 935.

"There is perhaps at the present time a tendency to disparage too much scientific observations which have no experimental content, and indeed I was somewhat startled this year to know that a certain body had turned down some proposals carefully thought out by a Committee of the Society on the ground that the intended work was merely the collecting of data. A great deal of pathology, at least in the past, has been data collecting, and it would be a bold man who would proclaim that this had been unfruitful. Perhaps I can illustrate my point adequately if I select one disease which is now a household word. I refer to coronary thrombosis, a condition which is responsible for much disability and many deaths and of which we hear a great deal too much in connection with our friends. Much of our knowledge of the underlying changes in this condition has been acquired by the classical methods of pathology, namely, observation of the diseased parts after death and the correlation of the findings with the symptoms that the patient had while alive." (Sir Howard Florey, P.R.S., Anniversary Meeting address, November 30.) 